\title{
Kinetics of Cadmium and Cobalt Desorption from Iron and Manganese Oxides
}

\author{
Clare A. Backes, Ronald G. McLaren, * Andrew W. Rate, and Roger S. Swift
}

\begin{abstract}
Oxides of $\mathrm{Fe}$ and $\mathrm{Mn}$ in soils are capable of sorbing large amounts of trace metal ions and can therefore be important in controlling trace metal concentrations in soil solution, and hence trace metal bioavailability in soils. There is, however, relatively little information on the rates of desorption of trace metals from oxide materials or on the factors affecting desorption rates. The objective of this study was to examine the kinetics of desorption of $\mathrm{Cd}$ and Co from two Fe oxides, goethite and ferrihydrite, and from two Mn oxides, hausinannite and cryptomelane. The concentrations of $\mathrm{Cd}$ and Co specifically sorbed by the oxides at $\mathrm{pH} 6.0$ were greater for the Mn oxides than for the Fe oxides. The metals were also much less readily desorbed from the Mn than the Fe oxides and, in general, Cd was more readily desorbed than Co from all four oxides. Increasing the initial sorption period from 1 to 15 wk substantially decreased the proportion of sorbed $\mathrm{Cd}$ or Co subsequently desorbed from goethite, with a similar but much smaller effect also observed with the Mn oxides. Desorption kinetics for both Cd and Co were found to be described well by assuming either the occurrence of two simultaneous first-order desorption reactions, or by a continuous distrihution of reaction sites, distributed lognormally with respect to desorption first-order rate constant. With increasing initial sorption period, the parameters ohtained from fitting either type of kinetic equation to the experimental data could be interpreted as indicating a movement of metal ions to sites with slower desorption reactions.
\end{abstract}

$\mathrm{T}$ HE BIOAVAILABILITY, and hence potential toxicity or deficiency, of a trace metal ion in the soil depends on its concentration in the soil solution and on the soil's ability to release trace metal ions from the solid phase to replenish those removed from solution by plants. Many previous studies have demonstrated that soils have substantial capacities to sorb trace metal ions from solution, and it is now generally accepted that solution metal concentrations are most likely to be controlled by sorption-desorption reactions at the surface of both inorganic and organic soil colloidal materials (Swift and McLaren, 1991). Oxides of $\mathrm{Fe}$ and $\mathrm{Mn}$ are one group of soil colloids that have been shown to be capable of sorbing large amounts of trace metal ions (e.g., McKenzie, 1972, 1980; Benjamin and Leckie, 1981; Padmanabham, 1983; Bruemmer et al., 1988; Zasoski and Burau, 1988). However, results from some of the relatively few desorption studies reported to date indicate that substantial proportions of the trace metals sorbed by oxides cannot be desorbed readily back into solution (McKenzie, 1967; McLaren et al., 1983, 1986; Padmanabham, 1983). Similar observations have been made during trace metal desorption studies from intact soils (e.g., Lehmann and Harter, 1984; Barrow, 1986; Hogg et al., 1993).

In soils, increasing the contact time between soil and sorbed trace metal has been shown to decrease the metal's subsequent ability to desorb from the soil (Barrow, 1986;

C.A. Backes, R.G. McLaren, and A.W. Rate, Dep. of Soil Science, P.O. Box 84, Lincoln Univ., Canterbury, New Zealand; and R.S. Swift, CSIRO Division of Soils, Private Bag no. 2, Glen Osmond, SA 5064, Australia. Received 14 Apr. 1994. *Corresponding author (mclaren@lincoln.ac.nz).

Published in Soil Sci. Soc. Am. J. 59:778-785 (1995).
Hogg et al., 1993) and, in the case of $\mathrm{Cu}$, reduce its availability to plants (Brennan et al., 1980). Such observations have been linked to the results of studies that, following the initial rapid sorption of trace metals by oxide materials, have indicated the presence of relatively slow continuing metal-oxide reactions (Benjamin and Leckie, 1981; Bruemmer et al., 1988). The relatively low reversibility of trace metal sorption by oxides (and soils), and the nature of the continuing reactions that, with time, can decrease metal desorption still further, are not clearly understood.

One simple explanation for the generally poor reversibility of trace metal sorption of oxides is that, since chemisorption is almost certainly involved, the activation energies for desorption may be much larger than those for sorption and thus rates of desorption at ambient temperature are likely to be much slower than rates of sorption (McBride, 1991). Other explanations involve the incorporation of the trace metal into the oxides. Naturally occurring $\mathrm{Fe}$ oxides are known to contain associated trace metals (Schwertmann and Taylor, 1989). Incorporation of the metal into the oxide would compensate charge imbalances often present in oxides due to crystal defect structures (Schwertmann et al., 1985; McKenzie, 1989). McKenzie (1970) found that the sorption of trace metals onto some Mn oxides involved the release of $\mathrm{Mn}^{2+}$ and other cations from the oxides, the trace metals replacing cations in the oxide structure. Diffusion of trace metal ions within solid oxide materials, following initial surface sorption, has also been proposed to account for decreased metal desorption with time (Barrow, 1986; Bruemmer et al., 1988; Barrow et al., 1989). Whether such a process involves solid diffusion into the lattice structure, which would be expected to be extremely slow, or diffusion of ions into very small pores and interparticle spaces remains to be determined (McBride, 1991). Indeed, current evidence for the existence of diffusive processes is mainly indirect, depending solely on the fitting of sorption data to various diffusion equations (e.g., Barrow, 1986; Bruemmer et al., 1988).

In an attempt to further elucidate the reactions of trace metals at soil oxide surfaces, we examined the effect of length of sorption period on the subsequent rates of desorption of $\mathrm{Cd}$ and $\mathrm{Co}$ from some $\mathrm{Fe}$ and Mn oxides. Cadmium was selected for this study as an example of an important pollutant metal. Cobalt is an essential micronutrient for grazing ruminants and is often applied to Co-deficient soils in New Zealand to increase herbage Co concentrations. Cobalt is also known to be strongly sorbed by Mn oxides (McKenzie, 1970).

Both batch and continuous-flow techniques have been used to investigate sorption and desorption processes in soils and oxide materials. The relative advantages and disadvantages of each technique have been discussed in detail by Sparks (1988). In batch techniques, since desorbed species are not removed, reverse reactions 
can occur, creating problems in the calculation of rate coefficients. In flow techniques, the continuous supply of solution acts as a sink for desorbed ions and thus the kinetic data obtained from continuous-flow techniques can be simpler to interpret than with batch techniques. For this reason, a flow technique was selected for use in this study.

\section{MATERIALS AND METHODS}

\section{Preparation of Oxides}

Goethite ( $\alpha-\mathrm{FeOOH}$ ) was prepared in polypropylene containers by increasing the $\mathrm{pH}$ of a solution of $0.025 \mathrm{M} \mathrm{Fe}\left(\mathrm{NO}_{3}\right)_{3}$ to $\mathrm{pH} 12$ with additions of $1 M \mathrm{KOH}$ and then allowing it to stand at $70^{\circ} \mathrm{C}$ for $48 \mathrm{~h}$ (Cornell and Giovanoli, 1987). Ferrihydrite was prepared by addition of $1 M \mathrm{NaOH}$ to $0.5 \mathrm{M} \mathrm{FeCl}_{2}$ solution to give a $\mathrm{pH}$ of 7 . Sodium metasilicate $\left(\mathrm{NaSiO}_{3}\right)$ was then added to provide $39 \mathrm{mMSi}$ and the solution aerated with $\mathrm{CO}_{2}$-free air for $24 \mathrm{~h}$ (Schwertmann and Thalmann, 1976; Karim, 1984). This procedure gave a mixture of ferrihydrite $\left(\mathrm{Fe}_{5} \mathrm{O}_{7} \mathrm{OH} \cdot 4 \mathrm{H}_{2} \mathrm{O}\right)$ and feroxyhite $\left(\delta^{\prime}-\mathrm{FeOOH}\right)$, another poorly ordered, large surface area Fe oxide (for simplicity, this sample will be referred to as ferrihydrite). Cryptomelane $\left(\mathrm{K}_{2} \mathrm{Mn}_{8} \mathrm{O}_{16}\right)$ was prepared by the addition of $400 \mathrm{~mL}$ of $0.45 \mathrm{M} \mathrm{KMnO}_{4}$ at $60^{\circ} \mathrm{C}$ to $500 \mathrm{~mL}$ of $0.5 \mathrm{M} \mathrm{MnSO}_{4} \cdot 4 \mathrm{H}_{2} \mathrm{O}$ in $2 \mathrm{M}$ acetic acid at $60^{\circ} \mathrm{C}$. The mixture was then boiled for $20 \mathrm{~min}$ (McKenzie, 1981). Hausmannite $\left(\mathrm{MnO} \cdot \mathrm{MnO}_{2}\right)$ was prepared by aerating a solution of $0.2 \mathrm{M} \mathrm{MnSO}_{4}$ and $0.36 \mathrm{M} \mathrm{KOH}$ for $24 \mathrm{~h}$ (adapted from McKenzie, 1970).

The oxides were separated from solution by centrifugation at $10000 \times g$ for $10 \mathrm{~min}\left(20^{\circ} \mathrm{C}\right)$, frozen at $-20^{\circ} \mathrm{C}$ and then freeze-dried. They were then washed several times with deionized water to remove excess soluble salts and again frozen and freezedried. The composition of each product was verified by $\mathrm{x}$-ray diffraction. The surface areas of the oxides were determined with ethylene glycol monoethyl ether (Carter et al., 1986) and the points of zero charge (pzc) by titration of the oxides in $\mathrm{NaNO}_{3}$ at different ionic strengths (van Raij and Peech, 1972).

\section{Sorption Isotherms}

Sorption isotherms were determined for each oxide-metal combination using a batch technique. Samples of oxide (50 $\mathrm{mg}$ ) were weighed into $35-\mathrm{mL}$ polypropylene vials, and 20 $\mathrm{mL}$ of solution were added to give final concentrations of $5 \times 10^{-4} M \mathrm{Co}\left(\mathrm{NO}_{3}\right)_{2}$ or $10^{-4} M \mathrm{Cd}\left(\mathrm{NO}_{3}\right)_{2}$ in a background electrolyte solution of $0.01 M \mathrm{Ca}\left(\mathrm{NO}_{3}\right)_{2}$. Small amounts of saturated solutions of $\mathrm{Ca}(\mathrm{OH})_{2}$ were also added to give a range of final $\mathrm{pH}$ values. The samples were shaken for $48 \mathrm{~h}$ at $20^{\circ} \mathrm{C}$, centrifuged at $10000 \times g$ for $10 \mathrm{~min}$, and then filtered through a 0.45- $\mu \mathrm{m}$ Millipore (Millipore Corp., Milford, MA) cellulose ester filter. Filtrate $\mathrm{pH}$ values were measured, and $\mathrm{Co}$ or $\mathrm{Cd}$ concentrations were determined as described below.

\section{Desorption Procedure}

Samples for desorption studies were prepared as above, but the samples were only shaken for $24 \mathrm{~h}$ before being allowed to stand at $20^{\circ} \mathrm{C}$ for either $1 \mathrm{wk}$ or between 12 and $15 \mathrm{wk}$. The contents of the vial were then filtered (by injection) through a weighed $25-\mathrm{mm}$-diam. Swinnex filter holder containing a $0.45-\mu \mathrm{m}$ Millipore cellulose ester filter. The filter holder plus contents were weighed after injection of the sample to determine the weight (volume) of solution remaining entrained with the oxide on the filter. The concentration of Co or Cd in the filtrate was determined so that both the amounts of metal sorbed and the amounts entrained could be determined. The amounts of entrained metal were subsequently subtracted from the amounts present in the first desorption fraction. Desorption of metals was induced by continuous peristaltic pumping of $0.01 M$ $\mathrm{Ca}\left(\mathrm{NO}_{3}\right)_{2}$ through the oxide on the filter at a flow rate of 2.5 to $3.0 \mathrm{~mL} \mathrm{~min}-1$. The $\mathrm{pH}$ of the eluent was adjusted to the $\mathrm{pH}$ of the metal-oxide under study, and the system was maintained at $20^{\circ} \mathrm{C}$ throughout the whole desorption period (up to $7 \mathrm{~h})$. Eluate fractions were collected every $120 \mathrm{~s}$ using a fraction collector. Cobalt or $\mathrm{Cd}$ concentrations were measured in all the initial fractions from each desorption run; however, as the experiments progressed and the rate of change of metal concentrations decreased, fewer fractions were analyzed. Each experimental treatment (i.e., oxide-metal-sorption period combination) was run in duplicate.

\section{Cobalt and Cadmium Analysis}

Cobalt and Cd concentrations in equilibrium solutions and eluates were determined by flame or graphite furnace atomic absorption spectrophotometry. For Cd determinations by graphite furnace, to overcome interference from $\mathrm{Ca}$, ammonium phosphate $(0.43 M)$ was added to the samples (Kaiser et al., 1981). Detection limits were 0.001 and $0.005 \mu \mathrm{g} \mathrm{mL}^{-1}$ for Cd and Co, respectively.

\section{Numerical Methods}

Desorption of metal ions, $M$, from a substrate (oxide material) having $n$ discrete, independent sites for metal ion binding, $S_{1} \ldots S_{n}$, may be represented by the following:

$$
M-S_{1}+\ldots \ldots .+M-S_{n} \rightleftarrows n M+S_{1}+\ldots \ldots .+S_{n}
$$

Where $M-S_{1} \ldots n$ represents the metal bound by sites $S_{1} \ldots S_{n}$. Simultaneous first-order desorption for this system may be expressed mathematically, as a function of time, by the following:

$$
C_{\mathrm{MS}}=\sum_{i=1}^{n} C_{i} \exp \left(-k_{i} t\right)
$$

where $C_{\mathrm{Ms}}$ is the concentration of metal ion sorbed to substrate $\mathrm{S}$ at time $t, C_{1} \ldots C_{n}$ are the initial concentrations $(t=0)$ of metal ion bound to sites $S_{1} \ldots . S_{n}$, and $k_{1} \ldots \ldots k_{n}$ are first-order rate constants for desorption of $M$ from sites $S_{1} \ldots \ldots S_{n}$. Equation [2] was formulated with the assumption that all metal ions would eventually $(t=\infty)$ desorb, i.e., $\sum_{i=1}^{n} C_{i}=C_{\text {zero }}$, where $C_{\text {zero }}$ is the total amount of metal sorbed at $t=0$. Equation [2] may be fitted to experimental data by optimizing $C_{i}$ and $k_{i}$ values. For the particular case of Eq. [2] where $n=2$, fitting to experimental data was achieved by optimizing values for $C_{1}$ (concentration of metal associated with the faster of two first-order reactions) and for $k_{1}$ and $k_{2}$ (rate constants for the two reactions). Since $C_{\text {zero }}$ was fixed by the experimental data, $C_{2}$ (concentration of metal associated with the slower of two first-order reactions) was in effect fixed by the fitted value of $C_{1}$ (i.e., $C_{2}=C_{\text {zero }}-C_{1}$ ).

Alternatively, the assumption of discrete, independent sites $S_{1} \ldots \ldots S_{n}$ can be replaced with the hypothesis that metal ion binding sites form a continuous distribution with respect to the first-order desorption rate constant. If this distribution is lognormal, the appropriate equation is (Rate et al., 1992)

$$
C_{\mathrm{MS}}=\frac{C_{\mathrm{des}}}{\sigma \sqrt{2 \pi}} \int_{-4 \sigma}^{+4 \sigma} \exp \left[\frac{-1}{2}\left(\frac{\kappa-\mu}{\sigma}\right)^{2}\right] \exp \left(-\mathrm{e}^{\kappa} t\right) \mathrm{d} \kappa \text { [3] }
$$


where $C_{\text {des }}$ is the amount of $M$ that desorbs; $\mu$ is the mean of the normal distribution in $\ln k$; $\sigma$ is the corresponding standard deviation, and $\kappa(=\ln k)$ is the variable of integration. As with Eq. [2], Eq. [3] was formulated with the assumption that all metal ions would eventually desorb, i.e., at $t=\infty, C_{\text {des }}=$ $C_{\text {zero. }}$ Equation [3] may be fitted to experimental data by optimizing values of $\mu$ and $\sigma$.

Parameter sets were optimized for Eq. [2], with $n=2$, and $\mathrm{Eq}$. [3] by nonlinear regression, using the multidimensional simplex method of Nelder and Mead (1965) to minimize a residual sum-of-squares term. For the lognormal distribution model, integrals were solved numerically using the Romberg method (Press et al., 1986). Optimization programs were written in FORTRAN using adaptations of code presented by Press et al. (1986).

\section{RESULTS AND DISCUSSION}

\section{Sorption of Cadmium and Cobalt}

The surface properties of the oxide materials prepared for this study are shown in Table 1. It was not possible to determine accurately the pzc of the Mn oxides. In the case of cryptomelane, the pzc is $<3.0$, and in this region, the titration curves were very flat; hence, using this method, it was impossible to define accurately the intersection point. For hausmannite, the pzc could not be determined due to extensive dissolution of this oxide below $\mathrm{pH}$ 5.0. The $\mathrm{x}$-ray diffraction patterns revealed that the goethite and hausmannite samples were strongly crystalline, the cryptomelane less so, and the ferrihydrite poorly crystalline.

Sorption of trace metals in soils takes place in the presence of solution concentrations of major cations (e.g., $\mathrm{Ca}^{2+}, \mathrm{Mg}^{2+}, \mathrm{K}^{+}, \ldots$ ), which are orders of magnitude higher than those of the trace metals. Under these conditions, as a result of mass action effects, sorption of trace metals by normal cation-exchange reactions is negligible (Swift and McLaren, 1991). Sorption of trace metals by soil is therefore considered to be due predominantly to specific sorption mechanisms (chemisorption). In this study, to simulate normal soil conditions and minimize cation exchange, sorption and desorption of $\mathrm{Cd}$ and $\mathrm{Co}$ were determined against a relatively high background concentration of $\mathrm{Ca}^{2+}$ ions. Thus, this study is concerned exclusively with specifically sorbed $\mathrm{Cd}$ and $\mathrm{Co}$.

Sorption of $\mathrm{Cd}$ and $\mathrm{Co}$ by the oxides as a function of $\mathrm{pH}$ is shown in Fig. 1. As a result of extensive dissolution of hausmannite under acid conditions, no data for this oxide are shown below $\mathrm{pH}$ 5.5. Sorption of the two metals by the oxides followed similar patterns. Cryptomelane, with a pzc below 3.0 and a high surface area, sorbed significant amounts of both metals even at relatively low $\mathrm{pH}$ values. At the other extreme, goethite,

Table 1. Surface properties of oxides.

\begin{tabular}{lcc}
\hline Oxide & Surface area & pzc† \\
\hline & $\mathrm{m}^{2} \mathrm{~g}^{-1}$ & \\
Goethite & 90 & 8.7 \\
Ferrihydrite & 505 & 5.6 \\
Hausmannite & 76 & $<5.0$ \\
Cryptomelane & 200 & $<3.0$ \\
\hline
\end{tabular}

$\dagger$ pzc $=$ point of zero charge. which had a relatively small surface area and a pzc of 8.7 , only showed significant sorption of the metals at $\mathrm{pH}$ values above 6.0. However, neither the data in Fig. 1 nor those in Tables 2 and 3 indicate the presence of consistent relationships between sorption of $\mathrm{Cd}$ or $\mathrm{Co}$ and surface area or pzc. For example, at a similar $\mathrm{pH}$ value, hausmannite, which has a much smaller surface area than cryptomelane (Table 1), sorbed substantially greater amounts of both $\mathrm{Cd}$ and Co per unit surface area (Tables 2 and 3). A similar comparison can also be made between ferrihydrite and goethite (Tables 2 and 3). Since, as discussed above, the retention of $\mathrm{Cd}$ and $\mathrm{Co}$ by the oxides is due to specific sorption reactions, it is indeed unlikely that the amounts of $\mathrm{Cd}$ or $\mathrm{Co}$ sorbed will be related solely to differences in surface area and pzc. Chemisorption does not necessarily involve retention by negatively charged sites, so that the charge characteristics of the surface, such as the pzc or cation-exchange capacity, will be less important than for sorption by cation exchange. The actual chemical structure of the oxide surface would seem more likely to have the major influence on specific sorption of trace metals by the surface.

The concentrations of $\mathrm{Co}$ and $\mathrm{Cd}$ used in this study
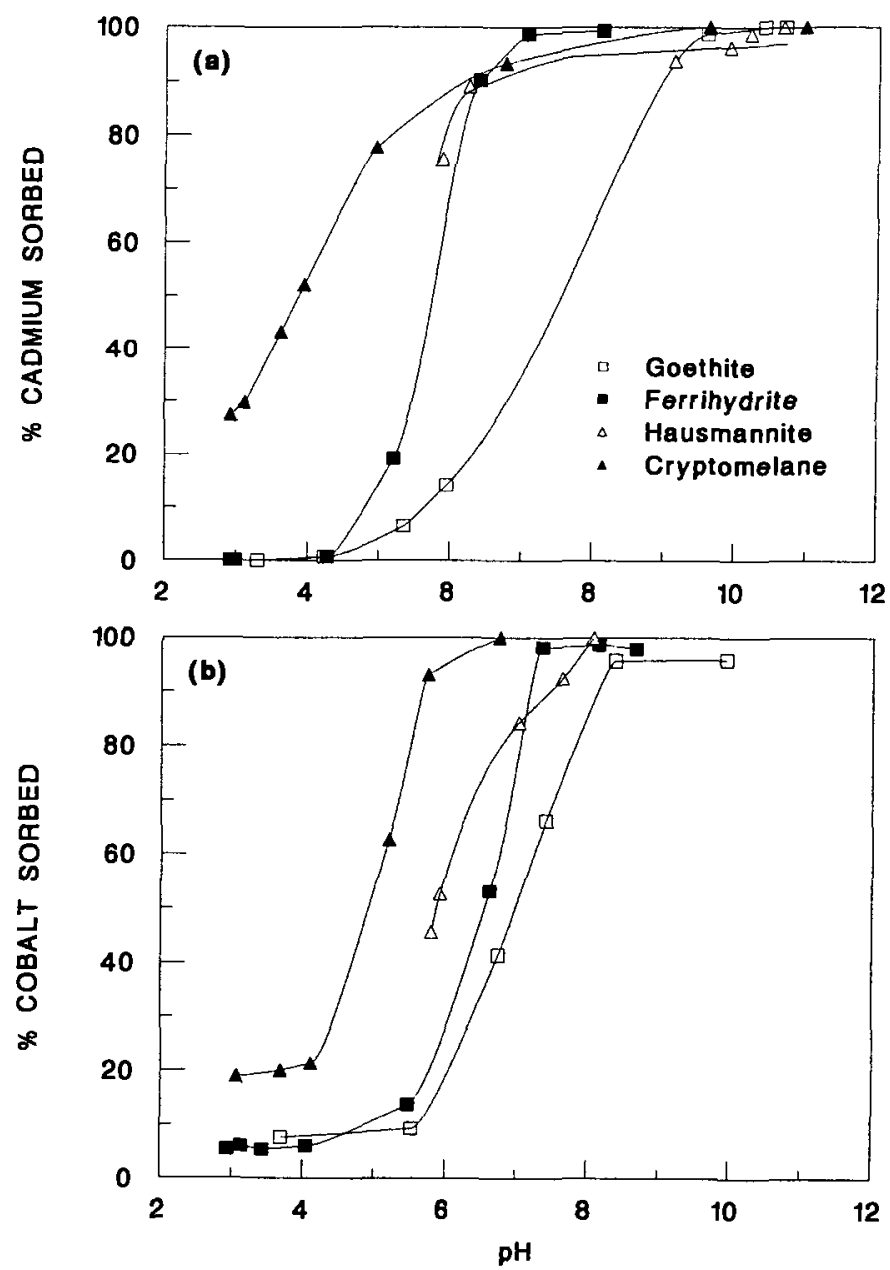

Fig. 1. Fractional sorption of (a) Cd(II) and (b) Co(II) on Fe and Mn oxides as a function of $\mathrm{pH}$ (initial metal concentrations, $\mathrm{Cd}=$ $10^{-4} M$, Co $=5 \times 10^{-4} M$. 
Table 2. Cadmium sorbed by oxides prior to desorption and proportions desorbed after $1.8 \times 10^{4} \mathrm{~s}(5 \mathrm{~h})$.

\begin{tabular}{|c|c|c|c|c|c|}
\hline \multirow[t]{2}{*}{ Oxide } & \multirow{2}{*}{$\frac{\begin{array}{c}\text { Sorption } \\
\text { period }\end{array}}{\text { wk }}$} & \multirow[t]{2}{*}{ pH } & \multicolumn{2}{|c|}{ Cd sorbed } & \multirow{2}{*}{$\begin{array}{c}\begin{array}{c}\text { Desorption after } \\
1.8 \times 10^{4} \mathrm{~s}\end{array} \\
\%\end{array}$} \\
\hline & & & $\mathrm{mmol} \mathrm{kg}^{-1}$ & $\mu \mathrm{mol} \mathrm{m} \mathbf{m}^{-2}$ & \\
\hline \multirow[t]{4}{*}{ Goethite } & 1 & 6.3 & 12.0 & 0.13 & 98 \\
\hline & 1 & 6.9 & 18.9 & 0.21 & 96 \\
\hline & 15 & 6.2 & 8.9 & 0.10 & 55 \\
\hline & 15 & 6.1 & 5.2 & 0.06 & 58 \\
\hline \multirow[t]{4}{*}{ Ferrihydrite } & 1 & 5.8 & 31.9 & 0.06 & 38 \\
\hline & 1 & 5.8 & 27.8 & 0.06 & 33 \\
\hline & 14 & 5.6 & 20.1 & 0.04 & 54 \\
\hline & 14 & 5.6 & 20.6 & 0.04 & 39 \\
\hline \multirow[t]{4}{*}{ Hausmannite } & 1 & 6.3 & 38.6 & 0.51 & 9 \\
\hline & 1 & 6.1 & 36.1 & 0.48 & 8 \\
\hline & 14 & 5.9 & 37.0 & 0.49 & 6 \\
\hline & 14 & 6.1 & 38.2 & 0.50 & 7 \\
\hline \multirow[t]{4}{*}{ Cryptomelane } & 1 & 5.9 & 38.2 & 0.19 & 17 \\
\hline & 1 & 5.6 & 37.4 & 0.19 & 18 \\
\hline & 15 & 5.7 & 39.2 & 0.20 & 5 \\
\hline & 15 & 5.9 & 39.5 & 0.20 & 6 \\
\hline
\end{tabular}

were dictated to a large extent by the analytical methods used for their determination. As a result, the concentrations of the metals sorbed by the oxides (Tables 2 and 3) were considerably higher than concentrations found in most natural unpolluted soils. However, trace metal concentrations in oxide fractions in soils can be orders of magnitude higher than in the bulk soil (Le Riche and Weir, 1963; Taylor and McKenzie, 1966). In addition, in soils heavily polluted with trace metals, concentrations of $\mathrm{Cd}$ as high as 13 to $15 \mathrm{mmol} \mathrm{Cd} \mathrm{kg}{ }^{-1}$ soil and of Co as high as 2.0 to $2.5 \mathrm{mmol} \mathrm{Co} \mathrm{kg}^{-1}$ soil have been recorded (Kabata-Pendias and Pendias, 1992).

\section{Desorption of Cadmium and Cobalt}

For the desorption studies, attempts were made to carry out all initial sorptions and subsequent desorptions as close to $\mathrm{pH} 6.0$ as possible. This $\mathrm{pH}$ value was selected as being appropriate to many agricultural $\mathrm{A}$ horizons in New Zealand. It was not practically possible to adjust all $\mathrm{pH}$ values to $\mathrm{pH} 6.0$ exactly, and in some cases, there were differences in $\mathrm{pH}$ (generally $<0.3 \mathrm{pH}$ units, except for the 1-wk Cd sorption experiment on goethite) between replicate oxide-metal combinations (Tables 2 and 3). Since slopes of the metal sorption-pH relationships for some of the oxides were relatively steep at $\mathrm{pH}$
6.0 (Fig. 1), in some cases, differences in $\mathrm{pH}$ around this value resulted in substantial differences between replicates in the amounts of metal initially sorbed. For this reason, data for individual replicates are presented rather than mean values. However, even in those cases where the amounts of metal sorbed differed between replicates, there was generally good agreement between replicates in the proportions of metal desorbed and in the rates of desorption (Tables 2-5).

Tables 2 and 3 show the amounts of metal sorbed by the oxides at $\mathrm{pH} \approx 6.0$ prior to desorption and the proportions desorbed after $5 \mathrm{~h}$. Irrespective of whether the amounts of metal sorbed are expressed on a weight or surface-area basis, the Mn oxides sorbed larger amounts of both $\mathrm{Co}$ and $\mathrm{Cd}$ than did the Fe oxides. For the Fe oxides, when sorption was expressed on a weight basis, ferrihydrite sorbed larger amounts of $\mathrm{Cd}$ and $\mathrm{Co}$ than did goethite, but the reverse was true for sorption expressed on a surface-area basis (Tables 2 and 3). Similarly for the Mn oxides, on a weight basis there was little difference in the concentrations of metals sorbed by hausmannite and cryptomelane, but on a surface-area basis hausmannite sorbed much higher concentrations of $\mathrm{Cd}$ and Co than did cryptomelane. Of the $\mathrm{Co}$ and $\mathrm{Cd}$ sorbed by the oxides, far greater proportions were able

Table 3. Cobalt sorbed by oxides prior to desorption and proportions desorbed after $1.8 \times 10^{4} \mathrm{~s}(5 \mathrm{~h})$.

\begin{tabular}{|c|c|c|c|c|c|}
\hline \multirow[t]{2}{*}{ Oxide } & \multirow{2}{*}{$\frac{\begin{array}{c}\text { Sorption } \\
\text { period }\end{array}}{\text { wk }}$} & \multirow[t]{2}{*}{ pH } & \multicolumn{2}{|c|}{ Co sorbed } & \multirow{2}{*}{$\frac{\begin{array}{c}\text { Desorption after } \\
1.8 \times 10^{4} \mathrm{~s}\end{array}}{\%}$} \\
\hline & & & mmol kg $\mathrm{kg}^{-1}$ & $\mu \mathrm{mol} \mathrm{m} \mathrm{m}^{-2}$ & \\
\hline Goethite & 1 & 6.5 & 43.8 & 0.49 & 48 \\
\hline & 1 & 6.3 & 62.8 & 0.70 & 47 \\
\hline & 14 & 6.0 & 30.7 & 0.34 & 23 \\
\hline & 14 & 5.8 & 37.8 & 0.42 & 19 \\
\hline \multirow[t]{4}{*}{ Ferrihydrite } & 1 & 6.4 & 100.1 & 0.20 & 37 \\
\hline & 1 & 6.2 & 79.3 & 0.16 & 38 \\
\hline & 12 & 6.0 & 81.6 & 0.16 & 32 \\
\hline & 12 & 5.5 & 67.2 & 0.13 & 42 \\
\hline Hausmannite & 1 & 6.5 & 188.2 & 2.48 & 5 \\
\hline & 1 & 6.2 & 189.7 & 2.50 & 5 \\
\hline & 14 & 6.2 & 197.5 & 2.60 & 2 \\
\hline & 14 & 6.2 & 196.8 & 2.59 & 2 \\
\hline \multirow[t]{4}{*}{ Cryptomelane } & 1 & 6.6 & 200.1 & 1.00 & 2 \\
\hline & 1 & 6.6 & 199.9 & 1.00 & 2 \\
\hline & 15 & 6.6 & 199.9 & 1.00 & 3 \\
\hline & 15 & 6.4 & 192.9 & 0.96 & 3 \\
\hline
\end{tabular}


Table 4. Fitted parameters derived from application of Eq. [2] $(n=2)$ and [3] to Cd desorption kinetics data $\left(C_{1}\right.$ and $C_{2}$ are initial concentrations; $k, k_{1}$, and $k_{2}$ are first-order rate constants for desorption; and $C_{\text {zero }}$ is the total amount of metal sorbed at time $=0$ ).

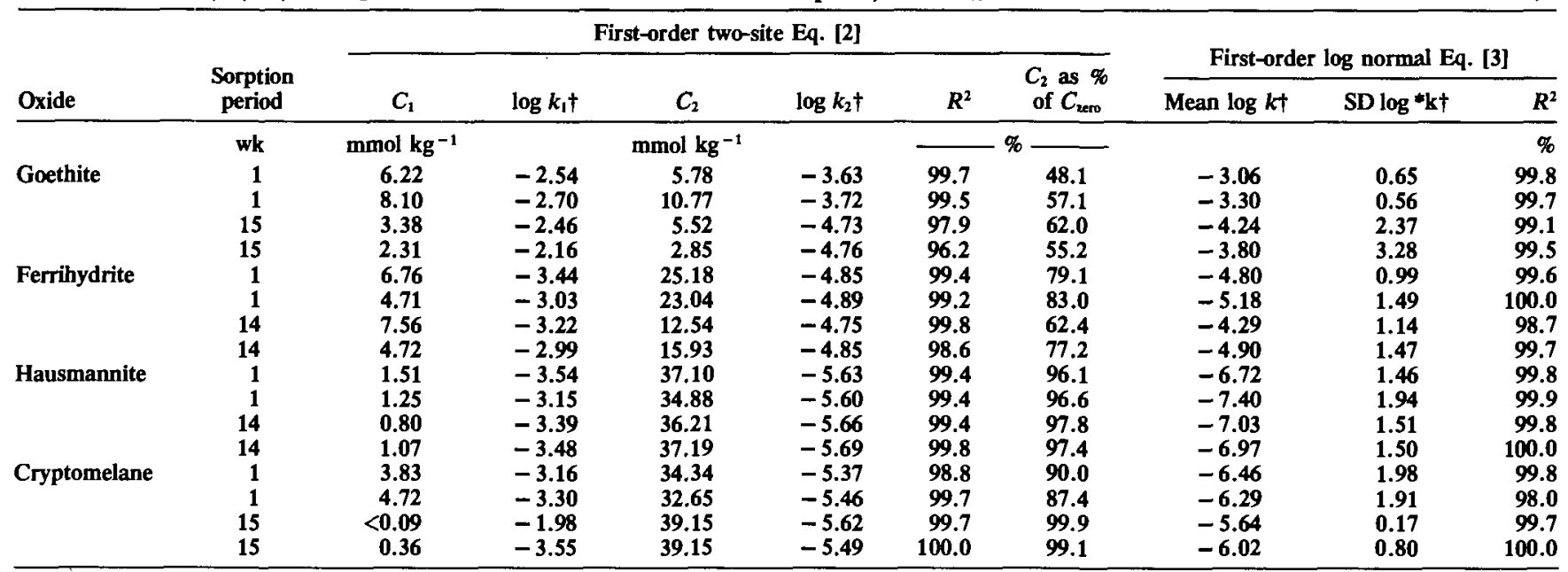

† Units for $k$ are $s^{-1}$.

to be desorbed from the Fe oxides than from the Mn oxides (Tables 2 and 3 ). Increasing the sorption period from $1 \mathrm{wk}$ to 12 to $15 \mathrm{wk}$ did not noticeably increase the amounts of Co or Cd sorbed by the oxides. However, in the case of the Fe oxides, any potential increase in sorption with time may have been masked by a decrease in $\mathrm{pH}$ during the same period (Tables 2 and 3). Protons are known to be released during the sorption of trace metals by oxides, possibly associated with hydrolysis of the metal at the oxide surface. In the case of the Mn oxides, even after a sorption period of only $1 \mathrm{wk},>95 \%$ of the Co or Cd added had been sorbed and any further sorption may have been difficult to detect due to the extremely low concentrations of metal remaining in solution. The high proportional sorption of the metals by the Mn oxides also probably accounted for the better replication between duplicate experiments for these materials compared with the $\mathrm{Fe}$ oxides.

Although significant effects of time on sorption of metals by oxides have been observed in some previous studies (e.g., Bruemmer et al., 1988), data from this study was unable to demonstrate a clear effect of length of sorption period on the amounts of Co or Cd sorbed. In some cases, however, increasing the sorption period had a marked effect on the subsequent rate of desorption of the sorbed metals. With goethite, increasing the length of sorption period substantially decreased the rate and amount of desorption of both Co and Cd. Similar trends were observed for Co sorbed by hausmannite and for $\mathrm{Cd}$ sorbed by cryptomelane (Tables 2 and 3 ).

\section{Kinetics of Cadmium and Cobalt Desorption}

Many different equations have been used to analyze the kinetics of ion desorption from soils or soil minerals (Skopp, 1986; Sparks, 1988). Initial examination of kinetic data from this study showed that desorption of both $\mathrm{Cd}$ and Co from all four oxides sets could be described by assuming that desorption was controlled by two simultaneous first-order reactions and that ultimately all the

Table 5. Fitted parameters derived from application of Eq. [2] $(n=2)$ and [3] to Co desorption kinetics data $\left(C_{1}\right.$ and $C_{2}$ are initial concentrations; $k, k_{1}$, and $k_{2}$ are first-order rate constants for desorption; and $C_{\text {zero }}$ is the total amount of metal sorbed at time $=0$ ).

\begin{tabular}{|c|c|c|c|c|c|c|c|c|c|c|}
\hline \multirow[b]{3}{*}{ Oxide } & \multirow{3}{*}{$\begin{array}{c}\text { Sorption } \\
\text { period }\end{array}$} & \multicolumn{6}{|c|}{ First-order two-site Eq. [2] } & \multirow{2}{*}{\multicolumn{3}{|c|}{ First-order lognormal Eq. [3] }} \\
\hline & & \multirow[b]{2}{*}{$C_{1}$} & \multirow[b]{2}{*}{$\log k_{1} \dagger$} & \multirow[b]{2}{*}{$C_{2}$} & \multirow[b]{2}{*}{$\log k_{2} \dagger$} & \multirow[b]{2}{*}{$R^{2}$} & \multirow{2}{*}{$\begin{array}{l}C_{2} \text { as } \% \\
\text { of } C_{2 \mathrm{ero}}\end{array}$} & & & \\
\hline & & & & & & & & Mean $\log k \dagger$ & SD $\log k \dagger$ & $R^{2}$ \\
\hline & wk & $\mathrm{mmol} \mathbf{k g}^{-1}$ & & $\mathrm{mmol} \mathrm{kg-}$ & & 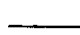 & 6 & & & $\%$ \\
\hline \multirow[t]{3}{*}{ Goethite } & $\begin{array}{l}1 \\
1\end{array}$ & $\begin{array}{l}15.27 \\
23.08\end{array}$ & $\begin{array}{l}-2.71 \\
-2.90\end{array}$ & $\begin{array}{l}28.51 \\
39.71\end{array}$ & $\begin{array}{l}-4.89 \\
-5.02\end{array}$ & $\begin{array}{l}93.5 \\
96.0\end{array}$ & $\begin{array}{l}65.1 \\
63.2\end{array}$ & $\begin{array}{l}-4.58 \\
-4.60\end{array}$ & $\begin{array}{l}2.26 \\
2.10\end{array}$ & $\begin{array}{l}99.6 \\
97.7\end{array}$ \\
\hline & 14 & 4.58 & -2.88 & 26.30 & -5.22 & 97.8 & 85.6 & -6.30 & 2.39 & 99.9 \\
\hline & 14 & 5.09 & -2.38 & 32.75 & -5.30 & 95.3 & 86.5 & -8.19 & 4.24 & 99.7 \\
\hline \multirow[t]{4}{*}{ Ferrihydrite } & 1 & 21.72 & -3.36 & 78.40 & -4.94 & 98.6 & 78.3 & -4.94 & 1.21 & 99.4 \\
\hline & 1 & 17.31 & -3.05 & 61.94 & -4.91 & 98.7 & 78.2 & -5.00 & 1.52 & 100.0 \\
\hline & 12 & 16.80 & -3.22 & 64.82 & -5.08 & 98.8 & 79.4 & -5.27 & 1.59 & 99.5 \\
\hline & 12 & 11.88 & -2.77 & 55.32 & -4.68 & 98.7 & 82.3 & -4.89 & 1.45 & 99.4 \\
\hline \multirow[t]{4}{*}{ Hausmannite } & 1 & 3.05 & -3.14 & 185.13 & -5.79 & 99.6 & 98.4 & -7.83 & 1.85 & 99.8 \\
\hline & 1 & 3.56 & -3.39 & 186.15 & -5.81 & 99.6 & 98.1 & -7.53 & 1.69 & 100.0 \\
\hline & 14 & 0.85 & $-\mathbf{3 . 1 3}$ & 196.67 & -5.96 & 99.9 & 99.6 & -7.53 & 1.40 & 99.7 \\
\hline & 14 & 1.53 & $-\mathbf{3 . 4 1}$ & 195.32 & -6.04 & 99.9 & 99.2 & -7.87 & 1.59 & 99.9 \\
\hline \multirow[t]{4}{*}{ Cryptomelane } & 1 & 0.51 & $-\mathbf{3 . 3 1}$ & 199.56 & -5.92 & 99.9 & 99.7 & -6.74 & 0.93 & 99.7 \\
\hline & 1 & 0.85 & $-\mathbf{3 . 7 5}$ & 199.05 & -6.00 & 100.0 & 99.6 & -6.87 & 0.99 & 100.0 \\
\hline & 15 & 0.34 & $-\mathbf{3 . 1 1}$ & 199.56 & -5.80 & 100.0 & 99.8 & -6.33 & 0.73 & 99.9 \\
\hline & 15 & 0.85 & $-\mathbf{3 . 3 5}$ & 192.09 & -5.88 & 100.0 & 99.6 & -6.90 & 1.08 & 99.9 \\
\hline
\end{tabular}

$\dagger$ Units for $k$ are $s^{-1}$. 

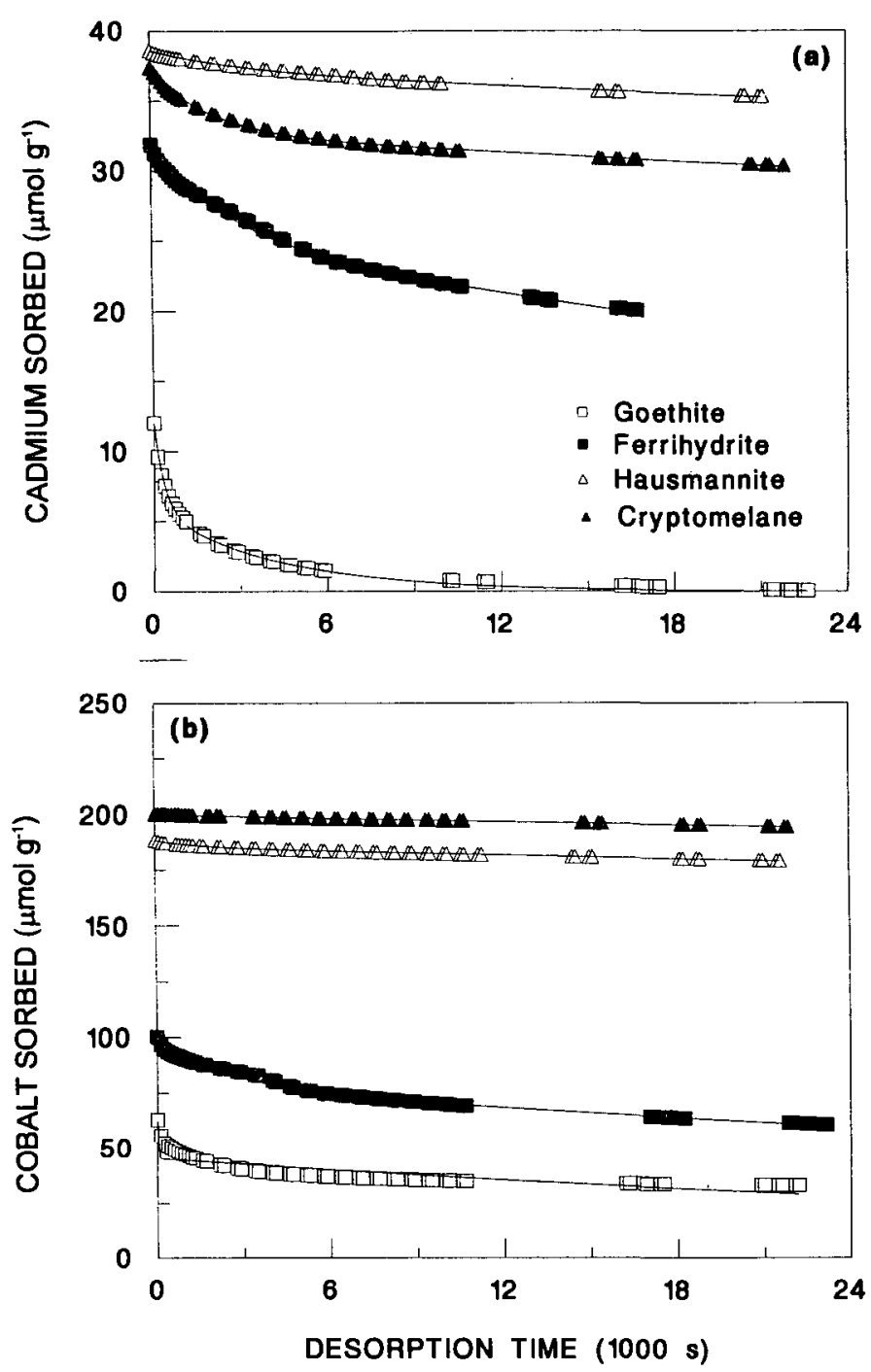

Fig. 2. 'Metal sorbed vs. desorption time for (a) Cd and (b) Co sorbed by $\mathrm{Fe}$ and $\mathrm{Mn}$ oxides (1-wk initial sorption period; symbols = experimental observations, lines = fits to Eq. [2]).

sorbed metals would be desorbed (Eq. [2], $n=2)$. Figure 2 shows some examples of the fits obtained with this equation for plots of sorbed $\mathrm{Cd}$ or $\mathrm{Co}\left(C_{\mathrm{MS}}\right)$ vs. length of desorption period $(t)$. In general, excellent fits were obtained and, with a few exceptions, $R^{2}$ values were $>99 \%$ (Tables 4 and 5). The optimized parameters for the various desorption experiments are shown in Tables 4 and 5 . However, since rate constants calculated from desorption data are dependent on the method used to measure desorption (Sparks et al., 1980), the optimized $k$ values should only be regarded as apparent rate constants (Skopp, 1986).

In effect, $k_{1}$ represents the rate constant for a relatively rapid desorption reaction with $t_{50}$ values ranging from 60 to $3.6 \times 10^{3} \mathrm{~s}(1 \mathrm{~h})$ and $k_{2}$ represents the rate constant for a much slower reaction with $t_{50}$ values, with two exceptions, between $3 \times 10^{4}$ and $8 \times 10^{5} \mathrm{~s}(\approx 8-200$ $\mathrm{h}$ ), where $t_{50}$ is the time required for $50 \%$ of the metal associated with a particular reaction to desorb from the oxide. There was little difference between $k_{1}$ values calculated for $\mathrm{Cd}$ and $\mathrm{Co}$ or for the different oxides,

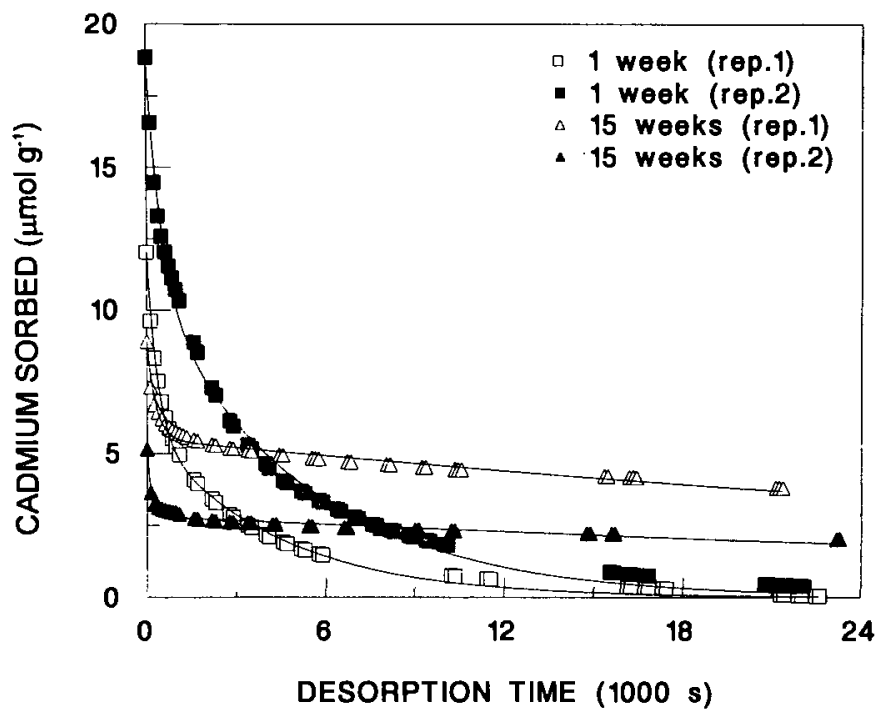

Fig. 3. Effect of initial sorption period on desorption of Cd from goethite (symbols = experimental observations, lines $=$ fits to Eq. [2]).

although values for goethite were slightly higher (faster desorption rates) than for the other oxides. Relatively small differences in $k_{1}$ values were observed between those systems with an initial sorption period of $1 \mathrm{wk}$ and those with longer periods (12-15 wk). There were, however, some differences between $\mathrm{Cd}$ and $\mathrm{Co}$ and between oxides in values for the rate constant for the slower reaction $\left(k_{2}\right)$. Values for $k_{2}$ were generally smaller (slower desorption rates) for Co than $\mathrm{Cd}$ and smaller for the $\mathrm{Mn}$ than the Fe oxides (Tables 4 and 5). The slow desorption of Co from Mn oxides in particular may be related to the theory (McKenzie, 1970) that following sorption by Mn oxides, $\mathrm{Co}^{2+}$ is oxidized to $\mathrm{Co}^{3+}$ and replaces $\mathrm{Mn}^{3+}$ in the crystal structure of the oxide.

For goethite, $k_{2}$ values also decreased when the initial sorption period was increased from 1 to $15 \mathrm{wk}$. In the case of $\mathrm{Cd}$, the effect of this decrease in desorption rate on the shape of the desorption curve can be seen in Fig. 3 . In addition to the decrease in $k_{2}$ values, for goethite, increasing the initial sorption period also increased the proportion of sorbed $\mathrm{Cd}$ or $\mathrm{Co}$ associated with the slower reaction $\left(C_{2}\right.$, see Tables 4 and 5). Increasing the length of the sorption period also resulted in an increased proportion of $\mathrm{Cd}$ sorbed by cryptomelane becoming associated with the slower reaction (Table 4). A similar, but less obvious, effect was observed for $\mathrm{Cd}$ and $\mathrm{Co}$ sorbed by hausmannite (Tables 4 and 5 ).

These increases in the proportions of sorbed metals associated with the slow reaction, together with the differences in $k_{2}$ values between metals, oxides, and initial sorption periods, would certainly explain the observed differences in the desorption percentages of $\mathrm{Cd}$ and $\mathrm{Co}$ from the oxides (Tables 2 and 3 ). A simple interpretation of the trends observed with an increased sorption period is that $\mathrm{Cd}$ and $\mathrm{Co}$ have moved from reaction sites associated with the fast desorption reaction to sites associated with the slower reaction. Alternatively, it is possible that changes have occurred at the original bonding site (e.g., hydrolysis of the metal or oxidation of $\mathrm{Co}^{2+}$ to 
$\mathrm{Co}^{3+}$ ) resulting in a slower desorption rate. Such changes might be related, at least in part, to any alterations in the structure and crystallinity of the oxides occurring during the longer periods of equilibration in aqueous suspension. However, Skopp (1986) pointed out the problems and ambiguities in interpreting time-dependent processes, particularly with regard to reaction mechanisms. The above simple interpretations do not necessarily explain the decrease in $k_{2}$ values obtained with goethite on increasing the sorption period.

Even though Eq. [2] gave excellent fits to the experimental data, it seems rather unlikely that there are only two types of reaction sites for Co or Cd associated with each of the oxide materials. As noted by Jardine and Sparks (1984), apparent desorption rate coefficients may be comprised of numerous diffusional and chemical reaction rates. The optimized desorption rate constants $\left(k_{1}\right.$ and $k_{2}$ ) could be thought of as representing averages for ranges of sites with either relatively fast or relatively slow reactions. However, by analogy with discrete site models of metal ion binding (Perdue and Lytle, 1983), such averages are unlikely to be meaningful. Nevertheless, decreases in $k_{2}$ values as a result of increasing the sorption period could represent a movement of metal ions to more slowly desorbing sites within the relatively slow reacting group of sites. Alternatively, the decrease in $k_{2}$ values could result from slower diffusion rates associated with the continuing movement of ions to relatively more inaccessible sites within the oxide materials (Barrow, 1986; Bruemmer et al., 1988). The fact that the decrease in $k_{2}$ and increase in $C_{2}$ values were most marked for goethite is probably related to the relatively small surface area (Table 1) and thus relatively large particle size of this oxide, with potentially longer intraparticle diffusion pathways. Although hausmannite also had a relatively low surface area, even after a 1-wk sorption period a very high proportion $(>96 \%)$ of $\mathrm{Cd}$ or Co sorbed by this oxide was already associated with the slower reaction sites (Tables 4 and 5).

Because of the uncertainty in interpreting optimized $k$ values for discrete site models, it was considered appropriate to attempt to fit the experimental data to a model based on not just two but a whole range of binding sites. The model selected is based on the hypothesis that the metal binding sites form a continuous lognormal distribution with respect to the first-order rate constant (Eq. [3]). The lognormal distribution model has previously been shown to give a good description of the dissociation of $\mathrm{Cu}^{2+}$ or $\mathrm{Ni}^{2+}$ from humic substances (Rate et al., 1992).

The lognormal model also produced excellent fits to the experimental data with $R^{2}$ values again mainly $>99 \%$ (Tables 4 and 5). The fitted parameters, $\mu$ (mean $\log k$ ) and $\sigma$ (standard deviation of $\log k$ ), for each oxidemetal combination are also shown in Tables 4 and 5. It should be noted that the lognormal model requires only two fitted parameters compared with the three required for the two discrete site model. Mean $\log k(\mu)$ values obtained from the lognormal model were comparable with the $k$ values obtained from the two discrete site model. In cases where the two discrete site model pre- dicted that $>80 \%$ of sorbed $\mathrm{Cd}$ or Co was associated with the slower reaction, $\mu$ values from the lognormal model were generally lower than the corresponding $k_{2}$ values. Where the two-site model predicted that substantially $<80 \%$ of sorbed $\mathrm{Cd}$ or Co was associated with the slower reaction, $\mu$ values fell between the values for $k_{1}$ and $k_{2}$ (Tables 4 and 5). Figure 4 shows the hypothetical lognormal distributions of first-order rate constants for $\mathrm{Cd}$ and Co sorbed by goethite after 1- and 15-wk sorptions. For both metals, there is a clear shift to lower $\mu$ values with the increased sorption period. This is consistent with the ideas discussed above of an overall movement of $\mathrm{Cd}$ or Co to sites with slower desorption reaction rates or, alternatively, it is possible that the lower $\mu$ result from chemical reconfiguration at the original bonding sites. In the case of $\mathrm{Cd}$, the increase in sorption period has also produced a substantially wider spread of $\log k$ values about the mean. An interpretation of this change is that $\mathrm{Cd}$ is initially bound by sites with a relatively narrow range of $\log k$ values but that, with time, the Cd becomes redistributed between sites with a much larger (and predominantly lower) range of $\log$ $k$ values.
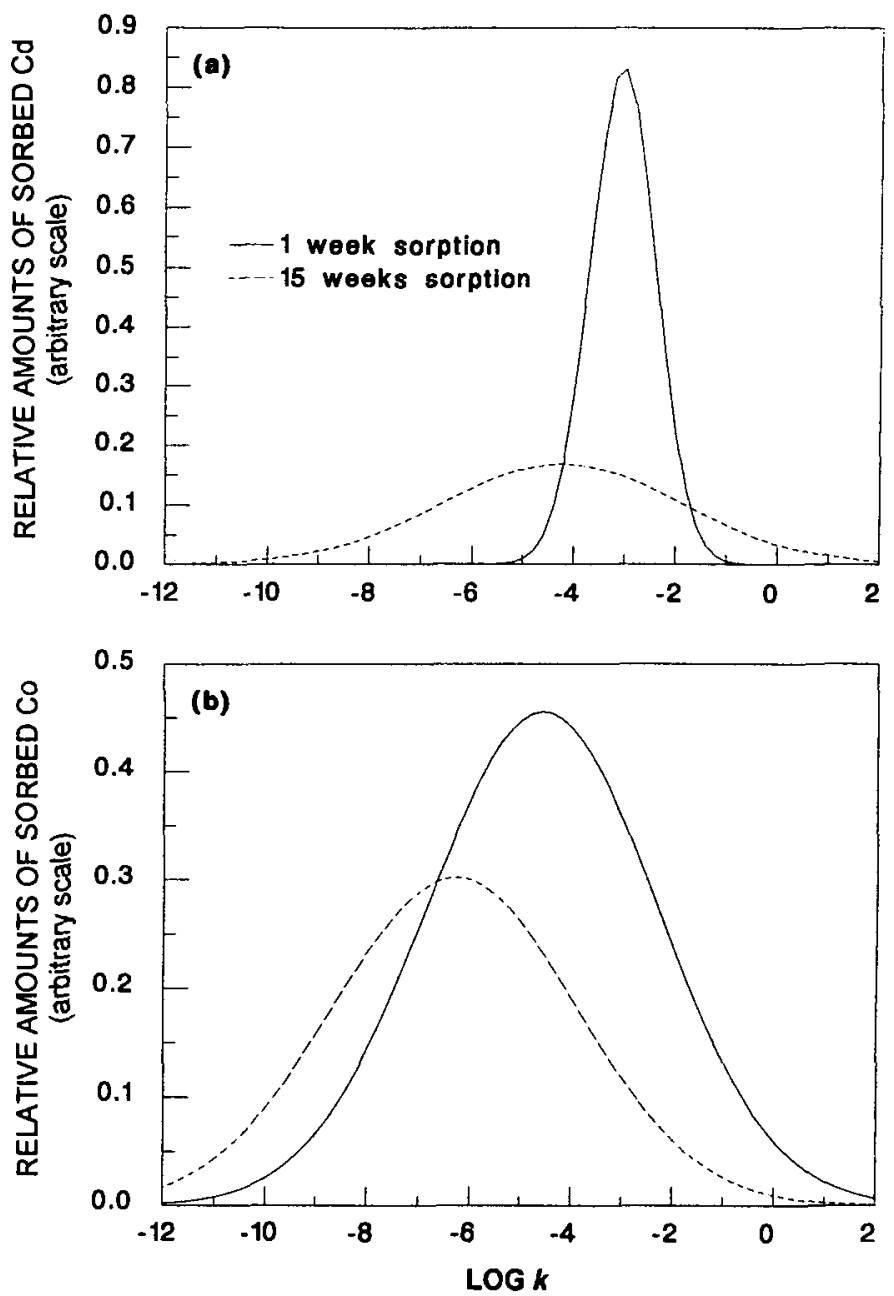

Fig. 4. Effect of initial sorption period on the hypothetical lognormal distributions of first-order rate constants for desorption ( $k$ ) of (a) Cd and (b) Co from goethite. 


\section{CONCLUSIONS}

It has been shown that substantial proportions of the $\mathrm{Cd}$ and Co sorbed by $\mathrm{Fe}$ and $\mathrm{Mn}$ oxides cannot readily desorb back into solution and, with goethite in particular, the longer the contact period between metal and oxide, the slower the subsequent rate of desorption. This clearly has implications for the bioavailability of metals sorbed by oxide materials in soils, whether the metal has been applied to the soil as a fertilizer (e.g., Co) or as a pollutant (e.g., Cd). Both the two first-order reaction site model and the lognormal distribution first-order model gave excellent fits to experimental kinetic data. The parameters obtained from the fits using either model provided useful information regarding possible changes in metal-oxide bonding with increasing sorption period. These changes can be interpreted as a movement of $\mathrm{Cd}$ or Co ions to sites with slower desorption reactions, possibly involving changes in both chemical and diffusion reaction rates.

\section{ACKNOWLEDGMENTS}

The senior author thanks the New Zealand University Grants Committee for the award of a postdoctoral scholarship, during the tenure of which this research was carried out. The technical assistance of L.J. Hassall is gratefully acknowledged and Dr. A.S. Campbell is thanked for carrying out the x-ray diffraction analysis of the oxides.

\section{REFERENCES}

Barrow, N.J. 1986. Testing a mechanistic model. II. The effects of time and temperature on the reaction of zinc with a soil. J. Soil Sci. 37:277-286.

Barrow, N.J., J. Gerth, and G.W. Bruemmer. 1989. Reaction kinetics of the adsorption and desorption of nickel, zinc and cadmium by goethite. II. Modelling the extent and rate of reaction. J. Soil Sci. 40:437-450.

Benjamin, M.M., and J.O. Leckie. 1981. Multiple-site adsorption of $\mathrm{Cd}, \mathrm{Cu}, \mathrm{Zn}$, and $\mathrm{Pb}$ on amorphous iron oxyhydroxide. J. Colloid Interface Sci. 79:209-221.

Brennan, R.F., J.W. Gartrell, and A.D. Robson. 1980. Reactions of copper with soil affecting its availability to plants. I. Effect of soil type and time. Aust. J. Soil Res. 18:447-459.

Bruemmer, G.W., J. Gerth, and K.G. Tiller. 1988. Reaction kinetics of the adsorption and desorption of nickel, zinc and cadmium by goethite. I. Adsorption and diffusion of metals. J. Soil Sci. 39: 37-52.

Carter, D.L., M.M. Mortland, and W.D. Kemper. 1986. Specific surface. p. 413-423. In A. Klute (ed.) Methods of soil analysis. Part 1. 2nd ed. Agron. Mongr. 9. ASSA and SSSA, Madison, WI.

Cornell, R.M., and R. Giovanoli. 1987. Effects of manganese on the transformation of ferrihydrite into goethite and jacobsite in alkaline media. Clays Clay Miner. 35:11-20.

Hogg, D.S., R.G. McLaren, and R.S. Swift. 1993. Desorption of copper from some New Zealand soils. Soil Sci. Soc. Am. J. 57: 361-366.

Jardine, P.M., and D.L. Sparks. 1984. Potassium-calcium exchange in multireactive soil system: I. Kinetics. Soil Sci. Soc. Am. J. 48: $39-45$.

Kabata-Pendias, A., and H. Pendias. 1992. Trace elements in soils and plants. 2nd ed. CRC Press, Boca Raton, FL.

Kaiser, M.L., S.R. Koirtyohann, and E.J. Hinderberger. 1981. Reduction of matrix interferences in furnace atomic absorption with the L'Vov platform. Spectrochim. Acta 36B:773-783.

Karim, Z. 1984. Characteristics of ferrihydrites formed by oxidation of $\mathrm{FeCl}_{2}$ solutions containing different amounts of silica. Clays Clay Miner. 32:181-184.

Lehmann, R.G., and R.D. Harter. 1984. Assessment of copper-soil bond strength by desorption kinetics. Soil Sci. Soc. Am. J. 48: 769-772.

Le Riche, H.H., and A.H. Weir. 1963. A method of studying trace elements in soil fractions. J. Soil Sci. 14:225-235.

McBride, M.B. 1991. Processes of heavy and transition metal sorption by soil minerals. p. 147-175. In G.H. Bolt et al. (ed.) Interactions at the soil colloid-soil solution interface. Kluwer Academic Publ., Dordrecht, the Netherlands.

McKenzie, R.M. 1967. The sorption of cobalt by manganese minerals in soils. Aust. J. Soil Res. 5:235-246.

McKenzie, R.M. 1970. The reaction of cobalt with manganese dioxide minerals. Aust. J. Soil Res. 8:97-106.

McKenzie, R.M. 1972. The sorption of some heavy metals by the lower oxides of manganese. Geoderma 8:29-35.

McKenzie, R.M. 1980. The adsorption of lead and other heavy metals on oxides of manganese and iron. Aust. J. Soil Res. 18:61-73.

McKenzie, R.M. 1981. The surface charge on manganese dioxides. Aust. J. Soil Res. 19:41-50.

McKenzie, R.M. 1989. Manganese oxides and hydroxides. p. 439464. In J.B. Dixon and S.B. Weed (ed.) Minerals in soil environments. 2nd ed. SSSA Book Ser. 1. SSSA, Madison, WI.

McLaren, R.G., D.M. Lawson, and R.S. Swift. 1986. Sorption and desorption of cobalt by soils and soil components. J. Soil Sci. 37: 413-426.

McLaren, R.G., J.G. Williams, and R.S. Swift. 1983. Some observations on the desorption and distribution behaviour of copper with soil components. J. Soil Sci. 34:325-331.

Nelder, J.A., and R. Mead. 1965. A simplex method for function minimization. Comput. J. 7:308-313.

Padmanabham, M. 1983. Comparative study of the adsorption-desorption behaviour of copper(II), zinc(II), cobalt(II) and lead(II) at the goethite-solution interface. Aust. J. Soil Res. 21:515-525.

Perdue, E.M., and C.R. Lytle. 1983. Distribution model for binding of protons and metal ions by humic substances. Environ. Sci. Technol. 17:654-660.

Press, W.H., B.P. Flannery, S.A. Teukolsky, and W.T. Vetterling. 1986. Numerical recipes - The art of scientific computing. Cambridge Univ. Press, Cambridge, England.

Rate, A.W., R.G. McLaren, and R.S. Swift. 1992. Evaluation of a log-normal distribution first-order kinetic model for copper(II)humic acid complex dissociation. Environ. Sci. Technol. 26:24772483.

Schwertmann, U., P. Cambier, and E. Murad. 1985. Properties of goethites of varying crystallinity. Clays Clay Miner. 33:369-378.

Schwertmann, U., and R.M. Taylor. 1989. Iron oxides. p. 379-428. In J.B. Dixon and S.B. Weed (ed.) Minerals in soil environments. 2nd ed. SSSA Book Ser. 1. SSSA, Madison, WI.

Schwertmann, U., and H. Thalmann. 1976. The influence of [Fe(II)], [Si], and $\mathrm{pH}$ on the formation of lepidocrocite and ferrihydrite during oxidation of aqueous $\mathrm{FeCl}_{2}$ solutions. Clay Miner. 11:189-200.

Skopp, J. 1986. Analysis of time-dependent processes in soils. J. Environ. Qual. 15:205-213.

Sparks, D.L. 1988. Kinetics of soil chemical processes. Academic Press, New York.

Sparks, D.L., L.W. Zelany, and D.C. Martens. 1980. Kinetics of potassium desorption in soil using miscible displacement. Soil Sci. Soc. Am. J. 44:1205-1208.

Swift, R.S., and R.G. McLaren. 1991. Micronutrient adsorption by soils and soil colloids. p. 257-292. In G.H. Bolt et al. (ed.) Interactions at the soil colloid-soil solution interface. Kluwer Academic Publ., Dordrecht, the Netherlands.

Taylor, R.M., and R.M. McKenzie. 1966. The association of trace elements with manganese minerals in Australian soils. Aust. J. Soil Res. 4:29-39.

Van Raij, B., and M. Peech. 1972. Electrochemical properties of some Oxisols and Alfisols of the tropics. Soil Sci. Soc. Am. Proc. 36:587-593.

Zasoski, R.J., and R.G. Burau. 1988. Sorption and sorptive interaction of cadmium and zinc on hydrous manganese oxide. Soil Sci. Soc. Am. J. 52:81-87. 